\author{
G. A. Donker \\ M. Foets \\ P. Spreeuwenberg
}

\section{Epilepsy patients: health status and medical consumption}

Received: 7 October 1996

Received in revised form: 24 Februar 1997 Accepted: 26 Februar 1997
G. A. Donker $(\bowtie) \cdot$ M. Foets

P. Spreeuwenberg

NIVEL: Dutch National Survey

of General Practice, Postbus 1568, 3500 BN-Utrecht

Tel.: 030-2319946 (or: 0592-389407),

Fax: 030-2319290 (or: 0592-389418)
Abstract Objective: To study the health status and medical consumption of outpatients with active epilepsy in comparison with the general population.

Design: Descriptive population study (multi-stage random sample).

Setting: Structured questionnaire.

Patients: Thirty-nine epilepsy patients compared with a general population of 12,975.

Results: Epilepsy patients revealed poorer health, a higher mean complaint score (5.3 versus $3.7, P<$ $0.05)$, a higher score on the General Health Questionnaire $(P<0.05)$, a somewhat higher score on the biological problem list (BIOPRO) (1.8 versus $1.4, P>0.05)$, less active sports engagement (16\% versus $39 \%, P<0.01$ ), more fatigue (46 vs $29 \%, P<0.05$ ), dizziness (33 vs $10 \%, P<0.01$ ), nervousness (28 vs $18 \%, P>0.05)$, sleep disturbance (23 vs $15 \%, P>0.05)$ and excitability (33 vs $15 \%, P<0.01$ ) when compared with the general population. The BIOPRO showed problems in epilepsy patients on specific items related to self-confidence $(P<0.001)$. Epileptic patients do not show more absence due to illness, from work, school or at home (15 vs $18 \%, P>$ 0.05 ) and/or more problems at work or in the family when compared with the general population. Almost half of epilepsy patients had consulted a specialist in the past 2 months (46 vs $23 \%$ of the general population, $P<$ 0.001). Epilepsy patients consulted the family physician slightly more often than other responders (3.0 versus 2.3, $P>0.05$ ) and contacted the family physician's assistant considerably more often $(2.3$ versus $0.7, P<$ $0.001)$. One-third of epilepsy patients consulted an alternative healer in the past 5 years versus $14 \%$ in the general population $(P<0.001)$.

Conclusions: The study shows an excess of psychosocial problems and medical consumption in epilepsy patients, but not more absence from work or problems at work or in the family. Further development of a quality of life instrument specific to epilepsy is advised.

Key words Epilepsy · Psychosocial . Alternative medicine - General health questionnaire $\cdot$ Biological profile list

\section{Introduction}

Epilepsy is a common medical problem that affects about $2 \%$ of the population at some time in their lives [2, 20,33, 39]. In The Netherlands there is scarce evidence on the psychosocial consequences of the disorder for the patients and the impact on their quality of life [31]. International studies in which a number of psychosocial outcome variables are related to epilepsy indicate that in general patients with epilepsy experience anxiety and depression, loss of self-esteem, loss of control over their body; they 
have neuropsychological impairments and their social functioning is impaired where there are reactions to societal prejudice and discrimination $[4-8,12,13,19,21,24$, $25,28,29,32,34,37]$. However, most data come from hospital-based clinics in which patients with serious chronic disease are overrepresented. Population studies in epilepsy are scarce [20]. A Dutch study in general practice showed an excess of psychosocial comorbidity (Donker et al. 1997, unpublished). About 37\% of epilepsy patients in general practice were referred to a specialist [2]. Even studies in general practice are known to underestimate the prevalence of epilepsy and are therefore also an unreliable measure of the burden of epilepsy in society [2]. A lack of agreement between the general practitioner and neurologist on their specific roles in the care for epilepsy patients has been documented $[35,36]$. Care for epilepsy patients is fragmented and studies using either extramural or intramural sources to collect data do not provide insight into the health status and/or medical consumption of epilepsy patients in the general population [2]. The present study identified patients with active epilepsy in the population to examine health characteristics and medical consumption in comparison with the general population. The following questions will be asked:

1. To what extent is the health experienced of outpatients with active epilepsy different from the general population?

2. Do outpatients with active epilepsy show an excess of psychosocial problems compared with the general population?

3. To what extent is the lifestyle of outpatients with active epilepsy different from the general population?

4. To what extent does absence due to illness differ in outpatients with active epilepsy as compared with the general population?

5. To what extent does the medical consumption of epilepsy patients differ from that of the general population?

\section{Patients and methods}

Data from the Dutch National Survey of Morbidity and Intervention in General Practice were used to identify patients with epilepsy. This study was performed in 1987-1988 in a random sample of 161 Dutch general practitioners serving a practice population of about 335,000 patients $[1,15,16]$. Over $99.9 \%$ of the Dutch population is registered at a general practice. Part of the data of the National Survey was collected by means of an extensive structured questionnaire sent to a random sample of approximately $100 \mathrm{pa}-$ tients per practice registered with the participating general practitioners. The total random selection included 17,047 respondents (3.9\% of all registered patients); the response percentage for the total random sample was $77 \%$ in the general population and $83 \%$ in epilepsy patients [14]. The questionnaire was designed for use in a broad field and did not contain a direct question on epilepsy. Epilepsy patients could only be identified in contact registration in general practice with the help of The International Classification of Primary Care (ICPC-code N88) [17, 38]. A total of 902 epilepsy patients was identified in the participating practices. As a link could be made between contact registration and structured questionnaire, the random sample of epilepsy patients who had filled out a questionnaire could be identified. The yield among all epilepsy patients was $4.3 \%$, slightly higher than the anticipated $3.9 \%$ (of all registered patients). Questionnaires of a random selection of 39 epilepsy patients were analysed. In the random sample of 39 epilepsy patients there is an underrepresentation of teenagers.

A number of questions in the patient's questionnaire concerned health indicators. As indicators of perceived health status the following were selected:

- A question about health experienced categorized as good, moderate and poor.

- The number of complaints during the 2 weeks before the interview took place. The average complaint score was analysed from a total list of 42 possible complaints, compared with the same score in the general population. Neurological and psychological complaints included in this list were analysed and presented separately.

- The score on the General Health Questionnaire (GHQ), a psychiatric screening questionnaire, 30-item version, for tracing persons with possible psychiatric problems [18]. The GHQ was used only in analyses of persons aged 15 years and above. A score of 5 and higher, but especially of 10 and higher, is considered as indicating a risk for psychiatric problems [18]. Both critical limits are presented.

- The score on the biographic problem list (BIOPRO), a list of 22 questions measuring social problems [22]. Differences in mean score were compared between epilepsy patients and the general population. Specific questions from the BIOPRO anticipated to be possibly related to epilepsy were compared between the two groups as well.

The following life-style indicators were analysed and compared with the general population: use of alcohol and active sports engagement. These life style indicators were selected on the anticipated possible relationship with epilepsy based on the literature. Other life-style indicators such as smoking, diet and sleeping habits were not analysed, as a relationship with epilepsy was not anticipated.

Absence due to illness and medical consumption were investigated over the 2 months prior to the questionnaire. Absence due to illness included absence from work or school, or having to reduce homework for health reasons. Consultation of specialist and/or alternative healer was analysed. The questionnaire did not diversify on the type of specialist. Consultation of an alternative healer was analysed over a period of 5 years. Consultation of the family physician and the family physician's assistant was analysed separately over a period of 3 months. Data for this analysis were collected from contact registration in general practice. Other medical consumption such as consultation of a physical therapist and/or district nurse were considered less relevant in epilepsy patients.

The data were analysed by SPSS [27]. When comparing differences between epilepsy patients and the general population, data were adjusted for age and sex differences. Age and sex distribution in the Population Survey were used as a standard for age/sex adjustment. The Mantel-Haenszel Summary Chi Square test was used as a statistical test for linear associations after age/sex adjustment, $t$ test for comparing mean complaint score, BIOPRO, consultation of the family physician and of the family physician's assistant between epilepsy patients and the general population [30]. Regression analyses were taken into consideration, but not performed owing to the small sample size.

\section{Results}

Questionnaires were received from 39 out of 47 epilepsy patients (response rate of $83 \%$ ). Four respondents were 
Table 1 Results of questionnaire (adjusted for age and sex) with 95\% confidence intervals of epilepsy patients $(n=39)$ compared to the general population $(n=12975)(C I \text { confidence interval })^{\mathrm{a}}$

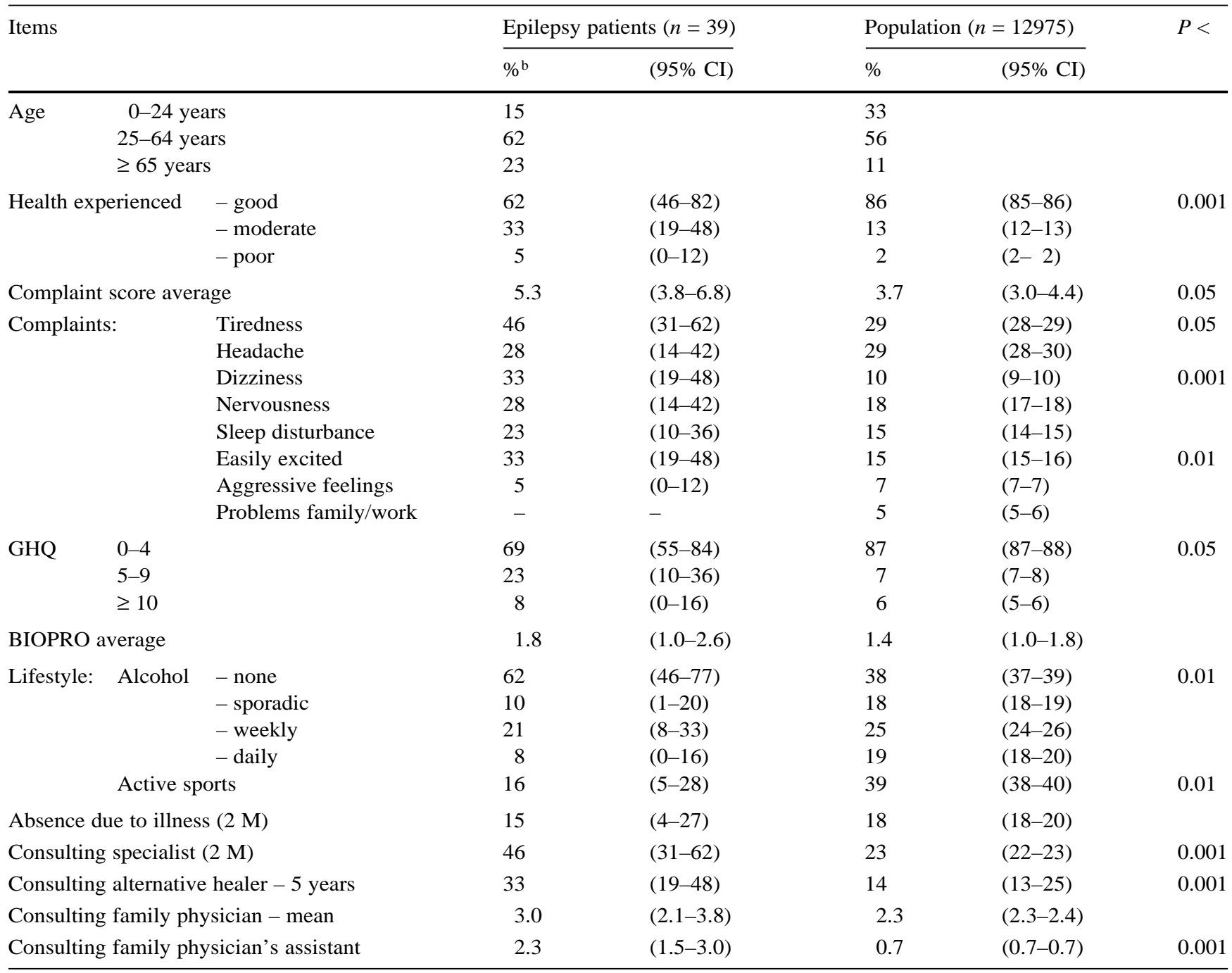

${ }^{a}$ Mantel-Haenszel Summary Chi-square test, t-test

${ }^{\mathrm{b}}$ Numbers without decimals concern percentages; numbers with decimals concern means

below 15 years of age (respectively 3, 4, 14 and 14 years). In these 4 children proxy interviews (parent interviews) were used. The separate questionnaires concerning lifestyle, biographic problem list and general health questionnaire were omitted in these 4 children. Twenty-one epilepsy patients were female (54\%) compared with $50 \%$ of all respondents. The mean age of epilepsy patients was 46 years (median 44) compared with 36 years (median 34) of all respondents. All results are adjusted for age and sex.

Although the majority $(62 \%)$ of interviewed epilepsy patients experience good health, the group with moderate $(33 \%)$ or poor $(5 \%)$ health is considerably larger than the general population (Table 1). The average complaint score appears to be higher in epilepsy patients. Out of a list of 42 possible complaints the average score in epilepsy patients was 5.3 after age/sex adjustment compared with 3.7 in the general population $(P<0.05, t$ test). Especially tiredness, dizziness and being easily excited were reported more often by epilepsy patients (Table 1). The interviews did not reveal more headache, aggressive feelings and/or problems at work in epilepsy patients than in the population at large (Table 1). Nervousness and sleep disturbance were close to being significant at $P=0.05$ (Table 1).

Epilepsy patients had a higher score on the GHQ $(P<$ $0.05)$, although most marked among epilepsy patients compared with the general population was in the moderate risk category of 5-9 (23 vs 7\%) and not in the high risk category of 310 ( 8 vs $6 \%$, Table 1$)$.

The average on the BIOPRO was 1.8 in epilepsy patients versus 1.4 in the general population $(P>0.05$, Table $1)$. When analysing the questions in the BIOPRO separately, epilepsy patients appeared to have the higher score 
on the question Do you face problems with what you find about yourself? Examples: Do you lack self-confidence? Are you often worried? Are you shy? (36\% yes, versus $13 \%$ in the general population, $P<0.001$, not in table). Questions concerning problems at work, problems in relationships, feelings of loneliness and concern about the future did not show different outcomes when compared with the general population.

Epilepsy patients are usually advised not to use alcohol, or to consume it moderately. They appear to use alcohol less frequently than other respondents in the National Survey $(72 \%$ none or sporadic versus $56 \%$ in the general population, $P<0.01$, Table 1). Compared with other respondents, epileptic patients were less often engaged in active sports (16 vs $39 \%$ in the general population, $P<$ 0.01 , Table 1).

Epilepsy patients did not have more absence due to illness in the 2 months prior to answering the questionnaire (Table 1). A relatively large proportion of epilepsy patients (44\%) consulted a specialist in the 2 months prior to the survey $(P<0.001)$. In 5 years one-third of epilepsy patients consulted an alternative healer compared with $14 \%$ in the general population $(P<0.001)$.

When analysing contacts in general practice, a distinction was made between consultation of the family physician and of the family physician's assistant (Table 1). The latter had considerably more contacts with epilepsy patients when compared with other responders of the questionnaire ( 2.3 versus 0.7 per 3 months, $P<0.001$ ), mainly for repeat drug prescription. Family physicians were consulted slightly more often by epilepsy patients compared with other responders (3.0 versus 2.3 per 3 months, $P>$ $0.05)$, but the difference was not significant.

\section{Discussion}

Structured questionnaires in 39 patients revealed poorer experienced health, a higher mean complaint score, a higher score on the General Health Questionnaire, less sports activity, more tiredness, dizziness, excitability and more medical consumption (including alternative medicine) than in the general population. Some other items like social problems and complaints of nervousness and sleep disturbance were also higher than in the general population, although not statistically significant owing to the small sample of epilepsy patients. The small sample size is a limitation of the study, and the study may therefore be seen as a feasibility study to indicate problem areas worthwhile studying on a larger scale.

A relatively large number of the epilepsy patients (44\%) consulted a specialist in the 2 months prior to answering the questionnaire. Besides consulting specialists, epilepsy patients appeared to consult alternative healers more than the general population. This has been reported in developing countries, but not in the Western world [3,
9]. Epilepsy patients contacted general practice more often than other respondents, especially the family physician's assistant for repeat drug prescription. This indicates that the population of epilepsy patients described in this article is in general a group of patients with active epilepsy using anti-epileptic drugs.

Our study analysed data from patient questionnaires. An analysis from contact registration in general practice in 902 epilepsy patients from which this study sample was drawn examined a number of sociodemographic variables (Donker et al. 1997, unpublished). An important finding of that study was that rates of unemployment and/or early retirement among epilepsy patients were comparable with those in the general population. Jacoby had the same finding in a group patients with well-controlled epilepsy in the United Kingdom [23]. These findings are supplementary to the finding in this study that epilepsy patients did not show more absence due to illness than the general population and did not face more problems at work or in the family. It may indicate that the stigma due to epilepsy and the related feelings of social isolation, given some prominence in literature, are not perceived as a problem. This was also noted by Chaplin and colleagues in a group of patients with newly diagnosed epilepsy [6]. They found that the psychosocial effects in newly diagnosed epilepsy were most closely related to the number of attacks experienced and the interval from the last seizure [5]. Our study concerned patients with a recent diagnosis as well as patients with well-controlled epilepsy. The finding that there is only a mild excess of social and psychological problems, as measured by respectively BIOPRO and GHQ-score, when compared with the general population, may also indicate that the stigmatizing effect of the diagnosis itself may be less important than previously thought when studies were mostly carried out in intramural settings in chronic patients. This is consistent with an English study in general practice and with a study carried out in Rochester [5, 37].

The mild excess of psychosocial problems found in epilepsy patients in this study may be correlates of medical factors such as the side-effects of drugs, number and recent date of seizures, and may be associated with stigma as well. Problems in very specific areas such as self-confidence and shyness were identified. This may have to do much with management in early phases of the disease and may have implications in counselling terms. Increased awareness of the psychosocial implications of epilepsy in the early phase may enhance appropriate adjustment. Little is known about the magnitude of the problem and how to approach it. Patients and physicians may differ in their perceptions of problems related to epilepsy. Most important is the awareness that psychosocial problems may arise even when seizures are infrequent. More systematic measurement and follow-up of psychosocial problems related to epilepsy seems useful.

Health-related quality-of-life studies in epilepsy have so far lacked suitable data-collection instruments. Re- 
cently a data collection instrument specific to epilepsy was developed, the Quality of Life in Epilepsy (QOLIE) instrument $[10,11,26]$. This is a general quality-of-life survey instrument (Rand 36 Item Health Survey) broadened with epilepsy-specific questions. The Rand 36 Item Health Survey is already translated and widely used in The Netherlands. The QOLIE-31 covers the following areas: seizure worry, overall quality of life, emotional wellbeing, energy-fatigue, attention-concentration, medication effects, social function and overall health. Validation studies of this instrument have recently started [11]. The instrument has recently been translated into Dutch. Further validation and translation of this data collection instrument seems a useful way to provide insight into psychosocial adjustment to epilepsy.
The study shows an excess of psychosocial problems and of medical consumption in epilepsy patients when compared with the general population, but not more absence from work or problems at work or in the family. Further development of a data collection instrument specific to epilepsy to measure health related quality of life seems likely to be useful.

Acknowledgements We thank the 161 general practitioners and their practice assistants, who collected data, without whom this study would not have been possible. We also thank J. van der Velden, MD, MPH, epidemiologist, for comments on an earlier version of this article.

\section{References}

1. Bensing JM, Foets M, Velden J van der, Zee J van der (1991) Dutch national survey in general practice (in Dutch). Huisarts Wet 34:51-61

2. Bosch JH van den, Kardaun JWPF (1994) The burden of diseases of the nervous system in the Netherlands (in Dutch) 138:1219-1224

3. Carod-Artal FJ, Domenech-Pascual EM (1995) Treatment of epilepsy among the Guarine (Palenque) tribes. Neurologia 10:394-395

4. Chaplin JE, Yepez R, Shorvon S, Floyd M (1990) A quantitative approach to measuring the social effects of epilepsy. Neuroepidemiology 9:151-158

5. Chaplin JE, Yepez Lasso R, Shorvon SD, Floyd M (1992) National general practice study of epilepsy: the social and psychological effects of a recent diagnosis of epilepsy. BMJ 304:14161418

6. Chaplin JE, Floyd M, Lasso RY (1993) Early psychosocial adjustment and the experience of epilepsy: findings from a general practice survey. Int J Rehabil Res 16:316-318

7. Collings JA (1990) Epilepsy and wellbeing. Soc Sci Med 31:165-170

8. Collings JA (1990) Psychosocial wellbeing and epilepsy: an empirical study. Epilepsia 32:418-426

9. Danesi MA, Adetunyi JB (1994) Use of alternative medicine by patients with epilepsy: a survey of 265 epileptic patients in a developing country. Epilepsia 35:344-351

10. Devinsky O (1993) Clinical use of the quality-of-life in epilepsy inventory. Epilepsia 34:S39-S44
11. Devinsky O, Vickrey BG, Cramer J, Perrine K, Hermann B, Meador K, Hays RD (1995) Development of the quality of life in epilepsy inventory. Epilepsia 36:1089-1104

12. Dodrill CB (1992) Neuropsychological aspects of epilepsy. Psychiatr Clin North Am 2:383-394

13. Dodrill CB, Breyer DN, Diamond MB, Dubinsky BL, Greary BB (1989) Psychosocial problems among adults with epilepsy. Epilepsia 25:168-175

14. Foets M, Sixma H (1991) Basisrapport: gezondheid en gezondheidsgedrag in de praktijkpopulatie. NIVEL, Utrecht

15. Foets $\mathbf{M}$, Velden J van der, Zee J van der (1986) Morbidity and interventions in general practice. A cross-national survey in The Netherlands. NIVEL, Utrecht

16. Foets M, Velden J van der (1990) Dutch national survey of general practice measurement instruments and procedures (in Dutch). NIVEL, Utrecht

17. Foets M, Velden J van der, de Bakker D (1992) Dutch National Survey of general practice. A summary of the survey design. NIVEL, Utrecht

18. Goldberg D (1972) The detection of psychiatric illness by questionnaire. Maudsley Monographs, no. 21. Oxford University Press, London

19. Goldstein J, Seidenberg M, Peterson R (1990) Fear of seizures and behavioral functioning in adults with epilepsy. J Epilepsy 3:101-106

20. Goodridge DMG, Shorvon SD (1983) Epileptic seizures in a population of 6000. BMJ 287:641-647
21. Hermann B, Whitman S (1992) Psychopathology in epilepsy. The role of psychology in altering paradigms of research, treatment and prevention. Am Psychol 47:1134-1138

22. Hosman CMH (1983) Psychosociale problematiek en hulp zoeken. Swets \& Zeitlinger, Lisse

23. Jacoby A (1992) Epilepsy and the quality of everyday life. Findings from a study of people with well-controlled epilepsy. Soc Sci Med 43:657-666

24. Jacoby A, Chadwick D (1992) Psychosocial problems in epilepsy. BMJ 30:117

25. Levine R, Banks S, Berg B (1988) Psychosocial dimensions of epilepsy: a review of the literature. Epilepsia 29: 805-816

26. Meador KJ (1993) Research use of the new quality-of-life in epilepsy inventory. Epilepsia 34:S34-S38

27. Norusis MJ (1990) SPSS/PC + V2.0 Base manual. SPSS International, Gorinchem

28. Perrine K, Congett S (1994) Neurobehavioral problems in epilepsy. Neurol Clin 12:129-151

29. Robertson M, Trimble M, Townsend H (1987) Phenomenology of depression in epilepsy. Epilepsia 28:364-366

30. Rosner B (1986) Fundamentals of biostatistics, 2nd edn. PWS, Boston, pp 302-368

31. Rutgers MJ Heisen TW (1982) Psychosocial and somatic aspects of epilepsy (in Dutch). Ned Tijdschr Geneeskd 126:798-803

32. Ryan R, Kempner K, Emlen AC (1980) The stigma of epilepsy as a self concept. Epilepsia 21:433-444 
33. Sander JWAS, Shorvon SD (1988)

Epilepsy in the community. J R Coll Gen Practitioners 88:51-52

34. Scambler G, Hopkins A (1986) Being epileptic: coming to terms with stigma. Social Hlth Illness 8:26-43

35. Stokx LJ, Kersten TJJMT (1990) Tasks of GPs and specialists in the care of patients with epilepsy (in Dutch). Ned Tijdschr Geneeskd 134:1943-1946
36. Stokx LJ, Kersten TJJMT, Velden J van der (1991) Dutch general practice care for patients with epilepsy: results from the Dutch National Survey of Morbidity and Interventions. Fam Pract 8:125-128

37. Trosstle JA, Hauser WA, Sharbrough FW (1989) Psychological and social adjustment to epilepsy in Rochester Minnesota. Neurology 39:633-637
38. Velden J van der, Schellevis FG, Steen J van der (1991) International Classification of Primary Care. Tabular list (in Dutch). NIVEL, Utrecht

39. Velden J van der, Bakker DH de, Claessens AAMC, Schellevis FG (1992) A Dutch National Survey of General Practice: morbidity in general practice. NIVEL, Utrecht 